This item was submitted to Loughborough's Research Repository by the author.

Items in Figshare are protected by copyright, with all rights reserved, unless otherwise indicated.

\title{
Accurate power sharing of hybrid energy storage system in DC shipboard power system based on quadratic programming algorithm
}

\author{
PLEASE CITE THE PUBLISHED VERSION
}

https://doi.org/10.1109/ISIE45063.2020.9152444

PUBLISHER

IEEE

\section{VERSION}

AM (Accepted Manuscript)

\section{PUBLISHER STATEMENT}

(c) 2020 IEEE. Personal use of this material is permitted. Permission from IEEE must be obtained for all other uses, in any current or future media, including reprinting/republishing this material for advertising or promotional purposes, creating new collective works, for resale or redistribution to servers or lists, or reuse of any copyrighted component of this work in other works.

\section{LICENCE}

\section{All Rights Reserved}

\section{REPOSITORY RECORD}

Shi, Tianling, Heyu Liu, Fei Wang, Shengqi Zhang, Hui Guo, and Zhengyu Lin. 2020. "Accurate Power Sharing of Hybrid Energy Storage System in DC Shipboard Power System Based on Quadratic Programming Algorithm". Loughborough University. https://hdl.handle.net/2134/12909809.v1. 


\section{Accurate Power Sharing of Hybrid Energy Storage System in DC Shipboard Power System Based on Quadratic Programming Algorithm}

\author{
Tianling Shi \\ School of Mechatronic Engineering and \\ Automation \\ Shanghai University \\ Shanghai, China \\ tianlingshi@shu.edu.cn \\ Shengqi Zhang \\ School of Mechatronic Engineering and \\ Automation \\ Shanghai University \\ Shanghai, China \\ shengqi_zhang8816@163.com
}

\author{
Heyu Liu \\ School of Mechatronic Engineering and \\ Automation \\ Shanghai University \\ Shanghai, China \\ 1095666722@qq.com \\ Hui Guo \\ School of Mechatronic Engineering and \\ Automation \\ Shanghai University \\ Shanghai, China \\ huiquo@shu.edu.cn
}

\author{
Fei Wang \\ School of Mechatronic Engineering and \\ Automation \\ Shanghai University \\ Shanghai, China \\ f.wang@shu.edu.cn \\ Zhengyu Lin \\ School of Mechanical, Electrical and \\ Manufacturing Engineering \\ Loughborough University \\ Leicester, UK \\ z.lin@lboro.ac.uk
}

\begin{abstract}
The DC shipboard power system (DC-SPS) can be regarded as an island microgrid, supplying energy to propulsion systems, service devices and advanced equipment in future ships. Ensuring accurate power sharing among distributed power sources and maintaining the stability of DC bus voltage in DCSPS are prerequisites to run system in security and economy. Therefore, an accurate power sharing method based on the quadratic programming algorithm is proposed in this paper. That method aims at minimizing the cost of voltage regulation in the consideration of state of charge (SoC) of each energy storage device (ESD). In detail, the target power is determined by the DC bus voltage deviation, and further distributed among various energy storage by quadratic programming accurately. With the control method, the DC bus voltage is maintained within the desired voltage range. Moreover, the method can meet the plug-and-play requirements of distributed power. The effectiveness of the proposed control method is verified by realtime simulation.
\end{abstract}

Keywords-DC shipboard power system (DC-SPS), hybrid energy storage system (HESS), quadratic programming, power sharing, state of charge (SoC)

\section{INTRODUCTION}

In response to the increasing demand for onboard electrical power and the progressively stricter environmental requirements, the extensive electrification of ship power has been a technological trend [1]-[4]. With the new concept of the ship integrated power system (IPS), the traditional ship mechanical propulsion system and power system will be integrated to supply energy to the propulsion system, communication and various loads through the power network, which realize the unified management of ship energy [5]. DC shipboard power system (DC-SPS) is an independent power system with multiple sources and loads. Compared with AC shipboard power system, DC-SPS has become the next generation of IPS technology route, which can reliably accommodate various distributed energy sources, simplify the energy conversion process and reduce the control complexity [6]. Coordinating the energy flow among multiple devices plays a significant role in operation stability and economy in DC-SPS. Particularly, energy storage devices (ESDs) act as either power generation or loads making the system more complex.
The introduction of ESD can facilitate the goals of power balancing and stabilizing the DC bus voltage, which can improve the stability and reliability of the system. However, the key technology is to design an effective power sharing method considering the state of charge (SoC) and cost of ESDs. In [7], in order to achieve balanced power in DC microgrids, the frequency division control of the hybrid energy storage system (HESS) has been proposed to assign the output power. However, consideration was not given to the SoC imbalance problem between battery and super capacitor (SC). In [8] and [9], the voltage and SoC of SC have been used as fuzzy logic control variables, but the voltage and SoC of the battery were not considered. In order to avoid damage to the life of the ESD caused by deep charging and discharging, the SoC of the ESD should be fully considered when designing the control method of microgrids. For that purpose, the droop coefficient was set to be inversely proportional to the exponential function of $\mathrm{SoC}\left(\mathrm{SoC}^{n}\right)$ in [10] and [11], where $n$ is identified as the convergence factor. However, the stability analysis and calculation of complex exponential inequalities are required to select the suitable " $n$ " value. Moreover, the voltage drop with droop control in microgrids was not considered in these studies.

In order to overcome those problems, an accurate power sharing control method based on the quadratic programming algorithm is proposed in this paper to assign the voltage regulation responsibilities of ESDs according to their ramp rates and capacities. The real-time simulation results show the effectiveness and feasibility of the control method. Major advantages of this control method are summarized as follows.

1) The power deviation determined by the DC bus voltage deviation is used as the target power, which can adjust the voltage drop in the DC-SPS.

2) The voltage regulation cost function is given in this paper, which can accurately evaluate the real-time voltage regulation capability of energy storage with different technical characteristics.

3) The proposed control method takes into account the different technical characteristics (e.g. maximum power, rated capacity, ramp rate and real-time SoC) of HESS to achieve the goal of distributing target power among different 
ESDs reasonably and accurately, which avoid the SoC of each ESS over-limit.

The rest of the paper is organized as follows. The components and simplified circuit model of DC-SPS are introduced in Section II. The architecture of HESS and proposed control method are presented in Section III. The quadratic programming algorithm is described in Section IV .The case studies and real-time simulation results are demonstrated in Section V. At last conclusions are drawn in Section VI.

\section{COMPONENTS AND SIMPLIFIED CIRCUIT MODEL OF DC-SPS}

\section{A. Components of DC-SPS}

To demonstrate the effectiveness of the proposed control method, the DC-SPS with IPS architecture is presented in Fig. 1. The system has two main AC turbine generators (MTG), two auxiliary AC diesel generators (ADG) as the source of power. Each generator supplies AC power with rated frequency and voltage to the DC bus through an $\mathrm{AC} / \mathrm{DC}$ converter. The DC / AC converter connected to the DC bus inverts the $\mathrm{DC}$ to $\mathrm{AC}$ with required frequency and voltage, which will be provided to the propulsion motor to drive the propellers. The energy storage device is connected to the DC bus through a bidirectional DC / DC converter. All loads of the DC-SPS are classified into four zones. All devices are connected to the DC bus through breakers and eventually form a ring structure, which ensures the system higher power supply reliability [12].

Super Capacitor : SC Main AC Turbine Generators : MTG Auxiliary AC Diesel Generators : ADG

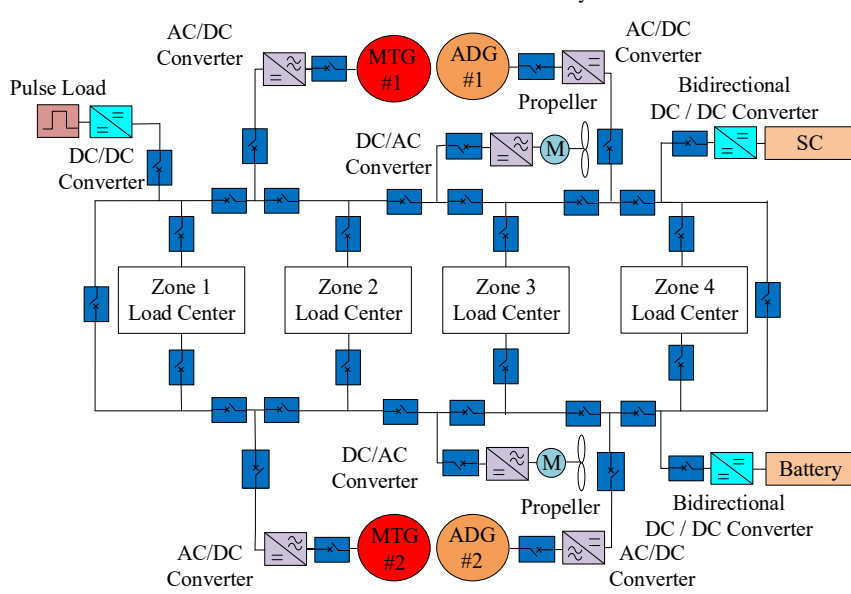

Fig. 1. Architecture of DC-SPS

\section{B. Simplified Circuit Model}

In DC-SPS, the governor is used to make MTG and ADG rotate at rated speed all the time. Each generator uses an uncontrolled diode rectifier as $\mathrm{AC} / \mathrm{DC}$ converter to connect with the DC bus. To output stable DC voltage, it only needs to control the excitation voltage of synchronous generator. Thus, to simplify the model of DC-SPS, power generation modules and energy storage modules are equivalent to ideal controlled DC voltage sources. Meanwhile, load centers can be equivalent to DC current sources. Assuming that the DC buses of port and starboard are connected by switches to form a common DC bus. The simplified circuit model of DC-SPS without considering the losses of transmission lines is shown in Fig. 2. The DC bus voltage $V_{\mathrm{dc}}$ can be described as follows:

$$
\frac{d V_{d c}}{d t}=\frac{\sum_{n=1}^{4} \mathbf{I}_{\mathbf{G}, \mathbf{n}}+\sum_{n=1}^{2} \mathbf{I}_{\mathbf{H E S S}, \mathbf{n}}-\sum_{n=1}^{4} \mathbf{I}_{\mathbf{L}, \mathbf{n}}}{C_{b u s}}
$$

where $C_{b u s}$ is the equivalent capacitance of DC bus, $\mathbf{I}_{\mathbf{G}}=\left[I_{M T G 1}, I_{M T G 2}, I_{A D G 1}, I_{A D G 2}\right]^{T}, \quad \mathbf{I}_{\mathbf{H E S S}}=\left[I_{B a t}, I_{S C}\right]^{T} \quad$ and $\mathbf{I}_{\mathbf{L}}=\left[I_{L 1}, I_{L 2}, I_{L 3}, I_{L 4}\right]^{T}$ represent the output current of power generation system, the output current of HESS and input current of load system, respectively.

As shown in (1), the DC bus voltage rises when the current algebraic sum is positive, that is the power absorbed by the DC bus is greater than the generated. Otherwise, the bus voltage drops. Therefore, the DC bus voltage can be measured and applied for the power sharing control of HESS.

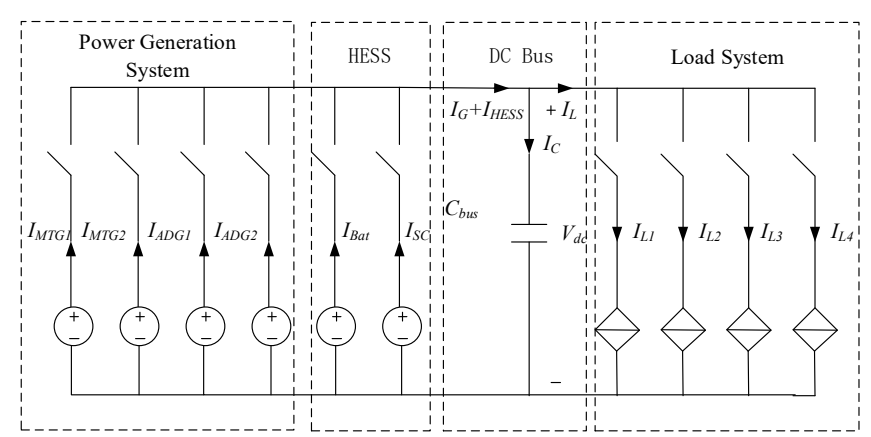

Fig. 2. The simplified circuit .model of DC-SPS

\section{ARCHITECTURE OF HESS AND PROPOSED CONTROL METHOD}

\section{A. Architecture of HESS}

The existing energy storage can be divided into two types: high energy density and high power density [13], [14]. 1) Energy storage media represented by lithium batteries, sodium-sulfur batteries and lead-acid batteries are belong to high energy density, which has the characteristics of low power density, limited cycle life, and slow dynamic response. 2) Energy storage media represented by SC, superconducting magnetic energy storage, and flywheel energy storage are high power density, which can provide or absorb high power in a short time. Therefore, an HESS composed of lithium battery and SC is adopted in this paper to combine their complementary features, which offers superior power and energy density than battery or SC alone.

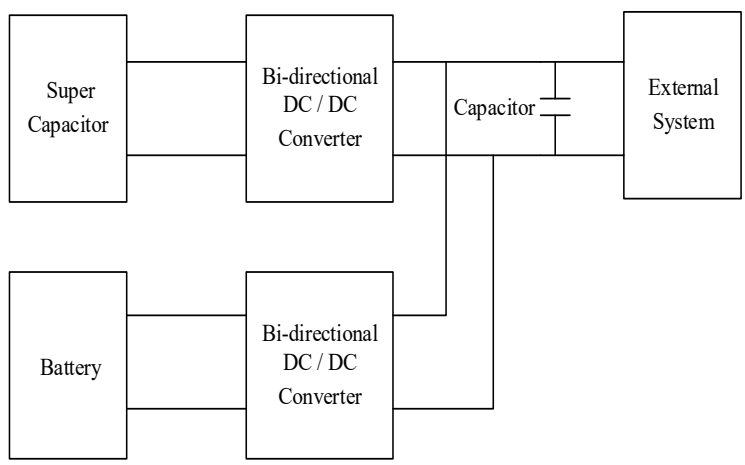

Fig. 3. The structural topology of active HESS 


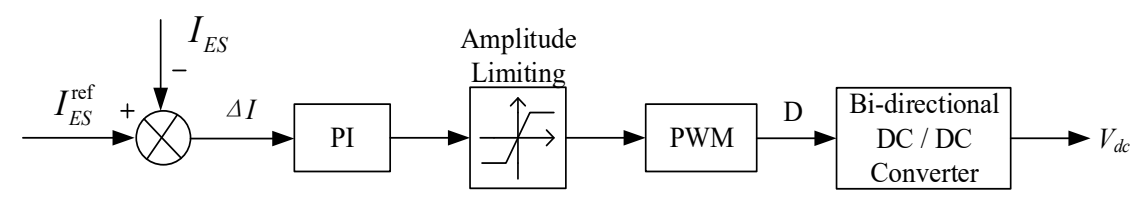

Fig. 4. The constant current charge / discharge control block diagram

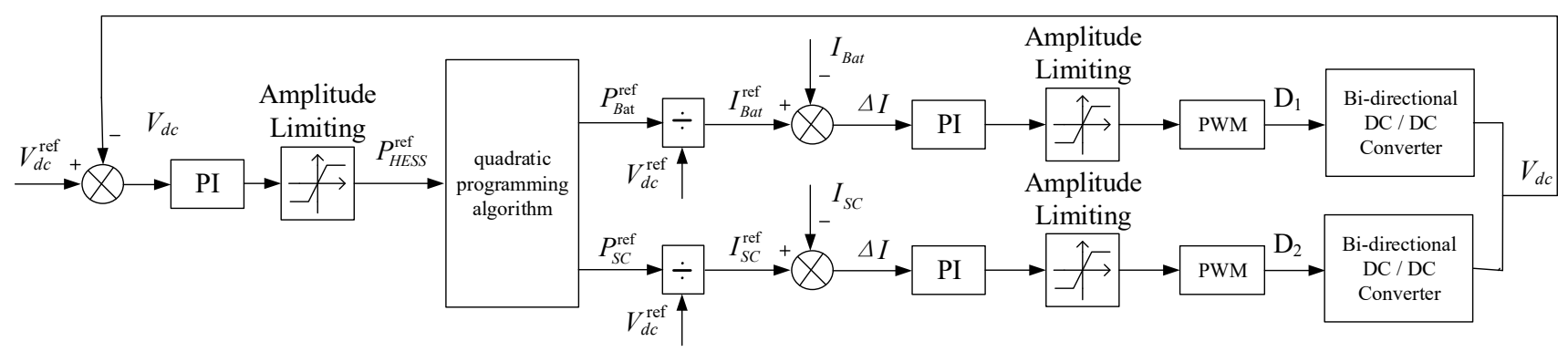

Fig. 5. Block diagram of the proposed control of HESS

As shown in Fig. 3, the structural topology of HESS is adopted in this paper. The battery and SC are connected to the DC bus through a bidirectional DC / DC converter. Based on two bi-directional DC / DC converters, the charge and discharge power of batteries and supercapacitors can be accurately controlled to respond to the power requirements of external systems actively.

\section{B. Control Method}

Usually, constant current charge / discharge control method is adopted to ensure that it does not cause drastic fluctuation in the DC bus voltage during charging and discharging. As shown in Fig. 4, $I_{E S}^{\text {ref }}, I_{E S}, \mathrm{D}, V_{d c}$ are the reference values of the charge / discharge current, the actual current of the energy storage module, the duty cycle signal, and the DC bus voltage, respectively. Therefore, the generation of $I_{E S}^{\mathrm{ref}}$ determines the control performance.

In order to maintain the stability of the bus voltage, and, at the same time, to take into account the SoC of the battery and the SC, it is necessary to optimize the distribution of HESS's target output power between the battery and the SC. The output power reference of each ESS is derived by the DC voltage control loop and the quadratic programming algorithm. The introduction of an PI regulator to DC voltage control can adjust the DC bus voltage drop caused by the droop control of generators, and its output value is used as the target power. As shown in Fig. 5, $V_{d c}^{\text {ref }}$ is the reference value of the DC bus voltage, $V_{d c}$ is the actual DC bus voltage, $P_{H E S S}^{\text {ref }}, P_{B a t}^{\text {ref }}$ and $P_{S C}^{\text {ref }}$ are the target output power of HESS, the battery and the SC, respectively. $I_{B a t}^{\mathrm{ref}}, I_{B a t}, I_{S C}^{\mathrm{ref}}$ and $I_{S C}$ are the current references and actual values of the battery and the SC, respectively.

\section{QUADRATIC PROGRAMMING ALGORITHM}

The quadratic programming algorithm is a common centralized algorithm to solve the convex optimization problem and obtain the global optimal solution where the objective function is a multivariate quadratic function with linear constraints [15]. To distribute the target output power among ESSs participating in voltage regulation, the cost function model considering $\mathrm{SoC}$ is established, the power reference values of the ESSs were taken as the variables, and the limits of power, capacity and ramp rate were taken as the constraints. The problem of minimizing the total cost of HESS can be transformed into a quadratic programming problem, which can track the voltage regulation signal, improve the optimization efficiency and fully considers the characteristics of different types of ESS, so as to allocate the reference value of charging / discharging power of different energy storage reasonably.

\section{A. Optimum Objective Function}

The voltage regulation loss of traditional generators mainly comes from the fuel cost, which has a quadratic function relationship with the output power [16]. Compared with the voltage regulation loss of traditional generators, a method to convert the voltage regulation loss of ESS into a quadratic function is presented in this paper according to the nonlinear relationship between the voltage regulation loss and real-time SoC of ESS. Voltage regulation loss function of single energy storage $\left(C_{i, k}\right)$ is given as $(2)$ :

$$
C_{i, k}\left(P_{i, k}, S o C_{i, k}\right)=a_{i} P_{i, k}^{2}+b_{i} S_{i}^{2}\left(S o C_{i, k}-S o C_{i}^{r e f}\right)^{2}
$$

The subscript $\mathrm{i}(\mathrm{i} \in \mathcal{J}=[1, \ldots, N])$ and $\mathrm{k}$ represent the ith energy storage participating in voltage regulation and the kth voltage regulation moment, respectively, where $\mathrm{N}$ is the total number of ESSs participating in voltage regulation, in this paper $\mathrm{N}=2, i=1$ represents the battery and $i=2$ represents the SC. $S_{i}$ is the rated capacity of energy storage. $P_{i, k}$ is the output power reference of each ESS, and it is defined that $P_{i, k}$ is positive when discharging, and negative when charging. The coefficients $a_{i}$ and $b_{i}$ reflect the square positive correlation between $C_{i, k}$ and output power, as well as the deviation of real-time SoC from the optimal value (denoted as $S o C_{i}^{\text {ref }}$, , respectively. The real-time SoC of ESS can be calculated as follows:

$$
S o C_{i, k}= \begin{cases}S o C_{i, k-1}-\eta_{i}^{\mathrm{c}} P_{i, k} \Delta t / S_{i}, & P_{i, k}<0 \\ S o C_{i, k-1}-\left(P_{i, k} / \eta_{i}^{\mathrm{d}}\right) \Delta t / S_{i}, & P_{i, k}>0\end{cases}
$$

where $\eta_{i}^{c}$ and $\eta_{i}^{d}$ represent the charge and discharge efficiency, respectively. $S o C_{i, k-1}$ is known at the kth moment, $\Delta t$ is the time interval of voltage regulation, $\Delta t=1 \mathrm{~s}$.

From (2) and (3), the quadratic function form of $\left(C_{i, k}\right)$ is expressed as: 


$$
\begin{gathered}
C_{i, k}= \begin{cases}\alpha_{i}^{c} P_{i, k}^{2}+\beta_{i, k}^{c} P_{i, k}+\gamma_{i, k}^{c}, & P_{i, k}<0 \\
\alpha_{i}^{d} P_{i, k}^{2}+\beta_{i, k}^{d} P_{i, k}+\gamma_{i, k}^{d}, & P_{i, k}>0\end{cases} \\
\text { where, }\left\{\begin{array}{l}
\alpha_{i}^{\mathrm{c}}=a_{i}+b_{i}\left(\eta_{i}^{\mathrm{c}} \Delta t\right)^{2} \\
\beta_{i, k}^{\mathrm{c}}=-2 b_{i} S_{i}\left(S o C_{i, k-1}-S o C_{i}^{\mathrm{ref}}\right) \Delta t \eta_{i}^{\mathrm{c}} \\
\gamma_{i, k}^{\mathrm{c}}=\gamma_{i, k}^{\mathrm{d}}=b_{i} S_{i}^{2}\left(S o C_{i, k-1}-S o C_{i}^{\mathrm{ref}}\right)^{2} \\
\alpha_{i}^{\mathrm{d}}=a_{i}+b_{i}\left(\Delta t / \eta_{i}^{\mathrm{d}}\right)^{2} \\
\beta_{i, k}^{\mathrm{d}}=-2 b_{i} S_{i}\left(S o C_{i, k-1}-S o C_{i}^{\mathrm{ref}}\right) \Delta t / \eta_{i}^{\mathrm{d}}
\end{array}\right.
\end{gathered}
$$

In (4), $S o C_{i}^{\text {ref }}$ is the given value, which is set as $50 \%$ in this paper. After the voltage regulation loss model of single energy storage is established, the minimum sum of voltage regulation loss of all energy storage can be taken as the optimum objective function:

$$
\min _{P_{i, k}} \sum_{i=1}^{N} C_{i, k}\left(P_{i, k}\right)
$$

as shown in (5), $N$ is the total number of energy storage participating in voltage regulation, and the free variable is the output power $P_{i, k}$ of each energy storage.

\section{B. Constraint Condition}

According to the control method shown in Fig. 5, the voltage regulation power demand $P_{H E S S}^{\text {ref }}$ tracked by HESS can be obtained at the $k$ th voltage regulation moment, which is denoted as $P_{k}^{\text {sum }}$ and taken as the equality constraint:

$$
\sum_{i=1}^{N} P_{i, k}=P_{k}^{\mathrm{sum}}
$$

Each energy storage unit is subject to power, ramp rate and SoC limits:

$$
\begin{gathered}
P_{i}^{\min } \leq P_{i, k} \leq P_{i}^{\max } \\
S o C_{i}^{\min } \leq S o C_{i, k} \leq S o C_{i}^{\max } \\
R_{i}^{\min } \leq \frac{P_{i, k}-P_{i, k-1}}{\Delta t} \leq R_{i}^{\max }
\end{gathered}
$$

where $S o C_{i}^{\min }$ and $S o C_{i}^{\max }$ are the upper and lower bound of real-time SoC, respectively. $R_{i}^{\min }$ and $R_{i}^{\max }$ are the upper and lower bound of ramp rate, respectively. $S o C_{i, k}$ can be derived from (3).

\section{Solution of Optimization Problems}

As shown in (10), the above optimization problem has been transformed into the standard form of quadratic programming. The optimal solution of the objective function can be obtained through the interior point method or the effective set method based on the quadratic programming function in MATLAB.

$$
\begin{gathered}
\min _{\boldsymbol{x}} \frac{1}{2} \boldsymbol{x}^{\mathrm{T}} \boldsymbol{H} \boldsymbol{x}+\boldsymbol{f}^{\mathrm{T}} \boldsymbol{x} \\
\text { s.t. }\left\{\begin{array}{l}
\boldsymbol{A} \boldsymbol{x}=\boldsymbol{b} \\
\boldsymbol{l} \leq \boldsymbol{x} \leq \boldsymbol{u}
\end{array}\right.
\end{gathered}
$$

where $\boldsymbol{x}$ is the free variable vector corresponding to $P_{i, k} . \boldsymbol{H}$ and $\boldsymbol{F}$ are the coefficient matrix of the quadratic term and the sequence vector of the primary term system of the objective function, respectively, corresponding to $\alpha_{i}$ and $\beta_{i, k}$ in (4). $\boldsymbol{A}$ is the vector of equality constraint coefficients, which is set to all 1-row vectors in this paper. $\boldsymbol{b}$ is the right end vector of the equality constraint corresponding to $P_{k}^{\text {sum }} . \boldsymbol{l}$ and $\boldsymbol{u}$ are the lower bound and upper bound column vectors of free variables, $P_{i, k}$, respectively. The internal elements $l_{i, k}$ and $u_{i, k}$ can be obtained by substituting inequality constraints (7) - (9)

$$
\begin{aligned}
& l_{i, k}=\max \left(P_{i}^{\min }, S_{i} \frac{S o C_{i}^{k-1}-S o C_{i}^{\max }}{\Delta t}, P_{i}^{k-1}+R_{i}^{\min } \Delta t\right)(11) \\
& u_{i, k}=\min \left(P_{i}^{\max }, S_{i} \frac{S o C_{i}^{k-1}-S o C_{i}^{\min }}{\Delta t}, P_{i}^{k-1}+R_{i}^{\max } \Delta t\right)(12)
\end{aligned}
$$

The optimal values $P_{i, k}$ obtained by the quadratic programming algorithm are used as the output power reference values at the $k$ th voltage regulation moment, $P_{B a t}^{\text {ref }}$ and $P_{S C}^{\text {ref }}$, from which the output current reference values $I_{B a t}^{\text {ref }}$ and $I_{S C}^{\text {ref }}$ are derived and transmitted to HESS.

\section{REAL-TIME SIMULATION RESULTS}

In order to verify the feasibility of the control method proposed in this paper, real-time simulations are carried out with the RT-LAB real-time simulator shown in Fig. 6. RT$\mathrm{LAB}$ is a digital and analog hybrid real-time simulator that is capable of simulating power system networks at a pace of realworld clock time. Due to the complex structure and various equipment of DC-SPS, the simulation model needs high precision. However, the off-line simulation software is limited by computer performance, simulation step size and simulation scale, which will lead to the actual time of off-line simulation of DC-SPS is much longer than the simulation time, or even overflow. Conversely, RT-LAB real-time simulator can shorten the simulation execution time and make the simulation results more practical, which overcome the disadvantages of off-line simulation effectively.

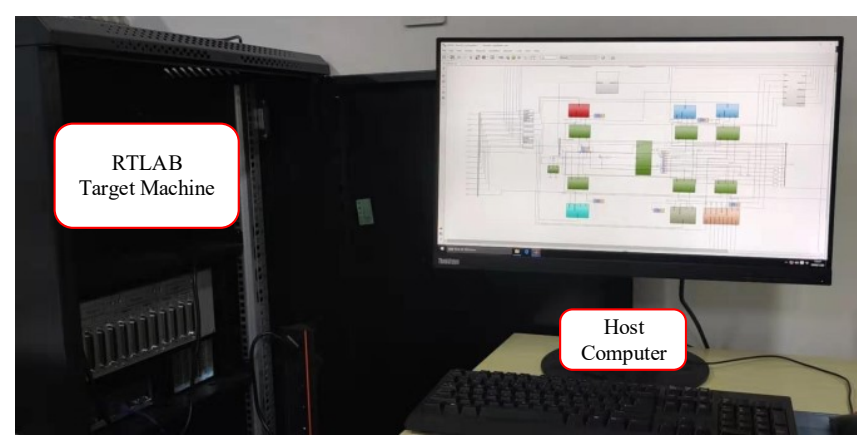

Fig. 6. Real-time simulation platform based on RT-LAB

TABLE I. THE KEY PARAMETERS OF DC-SPS

\begin{tabular}{|c|c|c|}
\hline \multirow{2}{*}{ Category } & Performance Index & Parameter \\
\hline \multirow{4}{*}{ DC Bus } & Rated DC bus voltage (V) & 540 \\
\cline { 2 - 3 } & Steady-state voltage tolerance & $\pm 5 \%$ \\
\cline { 2 - 3 } & Transient voltage range & $\pm 10 \%$ \\
\cline { 2 - 3 } & Voltage recovery time (s) & 2 \\
\hline
\end{tabular}




\begin{tabular}{|c|c|c|}
\hline \multirow{5}{*}{ Battery } & Rated capacity (kWh) & 6 \\
\hline & $\begin{array}{c}\text { Maximum power (discharge / } \\
\text { charge) }(\mathrm{kW})\end{array}$ & $20 /-20$ \\
\hline & $\begin{array}{c}\text { Ramp rate } \\
\text { (discharge / charge) }(\mathrm{kW} / \mathrm{h})\end{array}$ & $200 /-200$ \\
\hline & Initial SoC (\%) & 50 \\
\hline & Efficiency (\%) & 95 \\
\hline \multirow{5}{*}{$\mathrm{SC}$} & Rated capacity $(\mathrm{kWh})$ & 1.5 \\
\hline & $\begin{array}{c}\text { Maximum power (discharge / } \\
\text { charge) }(\mathrm{kW})\end{array}$ & $7 /-7$ \\
\hline & $\begin{array}{c}\text { Ramp rate } \\
\text { (discharge / charge) }(\mathrm{kW} / \mathrm{h})\end{array}$ & $400000 /-400000$ \\
\hline & Initial SoC (\%) & 50 \\
\hline & Efficiency (\%) & 90 \\
\hline MTG & Rated Power (kW) & 85 \\
\hline ADG & Rated Power (kW) & 16 \\
\hline
\end{tabular}

A DC-SPS simulation model with the same configuration in Fig. 1 is used as the study case. The key parameters of DCSPS are depicted in Table I. Two operation cases are set to validate the effectiveness of the proposed method. In the first case, the propulsion load increased from zero to its full power to simulate the acceleration process. In the second case, the load condition is set to simulate impulse loads, which performs a fast periodical change of power demand to verify the performance of the proposed method. The real-time simulation results of the two cases are shown in the following.

\section{A. Case 1: Acceleration Process}

The initialization of the system followed by an acceleration process is emulated. In Fig. 7, the real-time simulation by quadratic programming algorithm are shown. The simulation case can be divided into the following stages.

1) Stage $1\left(0-t_{1}\right)$ : The grid-forming process is emulated in this stage. The MTG \#1 and ADG \#1 accelerate from idle speed to its rated speed to supply power to the DC bus.

2) Stage $2\left(t_{1}-t_{5}\right)$ : From $t_{1}$, the propulsion load starts increasing to maximum in five stages. As load increases, the generators do not output the reference value of static power distribution completely. However, the HESS takes part of it first. The dynamic power reference of SC increases rapidly at the moment of load sudden change, which reduce the dynamic power of the generators. Then, the battery gradually tracks the power response to reduce the output power of the $\mathrm{SC}$, which can extend the life of the SC. The power distribution between the battery and the supercapacitor takes real-time SoC and ramp rate into account. The power reference value decreases with the decrease of the DC bus voltage fluctuation, so as to ensure that the generator has sufficient response time. The steady-state tolerance of the DC bus voltage is $3 \%$, the transient voltage range is $4 \%$, and the voltage recovery time is $1 \mathrm{~s}$. It can be known from the measurement and calculation that all the parameters meet the requirements given in Table 1.
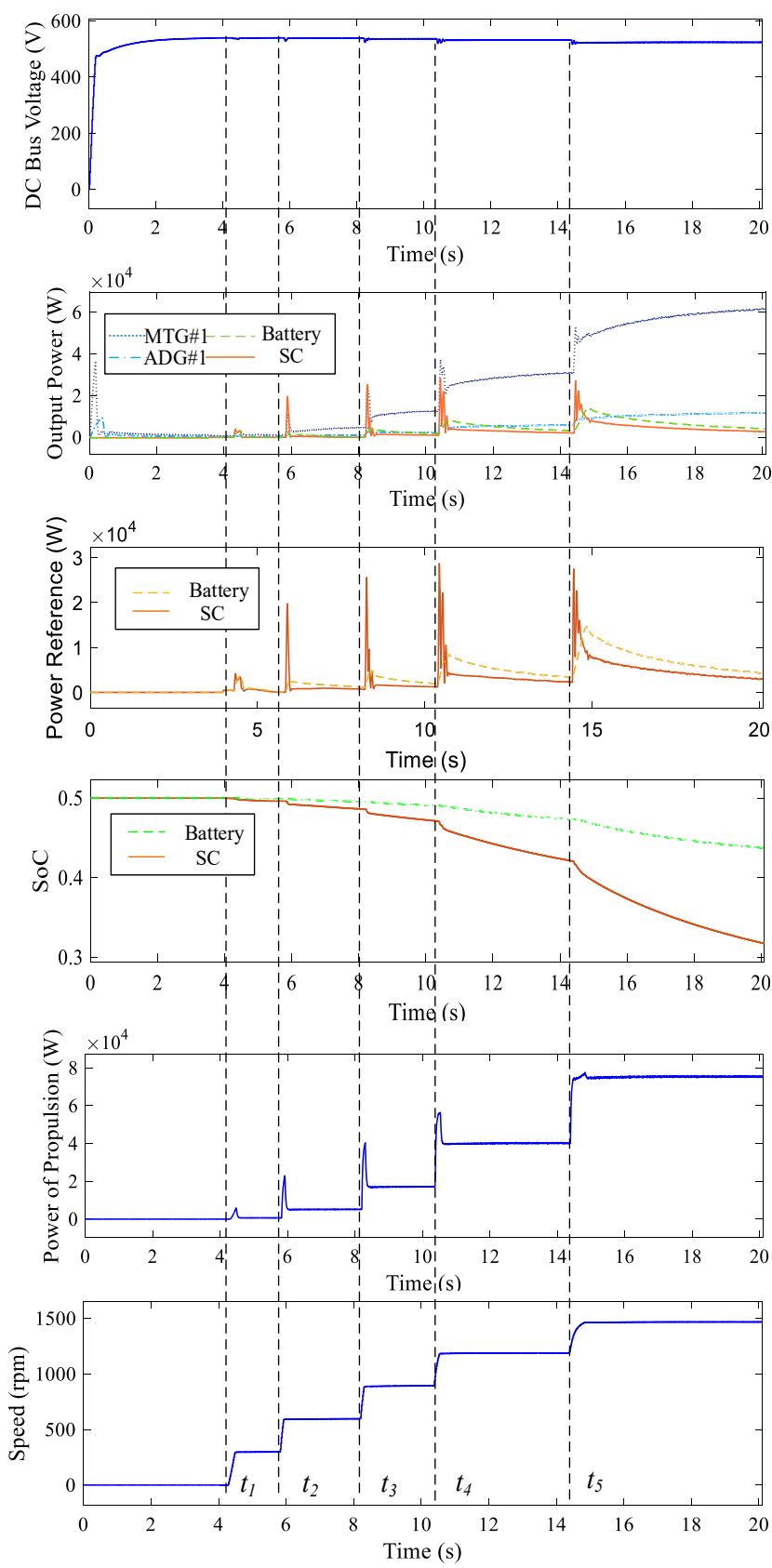

Fig. 7. Real-time simulation results of acceleration process

\section{B. Case 2: Impulse Loads}

In this case, impulse loads are used to simulate high dynamic loads. Two ADGs supply energy to DC-SPS. There are three periods in the simulation case, the rising edge of each period is $1 \mathrm{~s}$, the duration is $4 \mathrm{~s}$, the falling edge is $1 \mathrm{~s}$, and the pulse interval is $2 \mathrm{~s}$. Similarly, the power distribution between the SC and the battery takes into account the ramp rate, rated capacity and real-time SoC. However, since the loads increase at a certain slope, the SC does not have a sudden increase in output power shown in Fig. 7. As the dynamic response process is gradually, the ADGs have enough response time to avoid large voltage fluctuations. Compared to battery, the SC discharges and charges more rapidly during the rising and falling edges of impulse loads due to higher ramp rate. The steady-state tolerance of the DC bus voltage is $3.6 \%$, the transient voltage range is $3.8 \%$, and the voltage recovery time is $1 \mathrm{~s}$. Results meet the expected requirements given in Table 1 . 

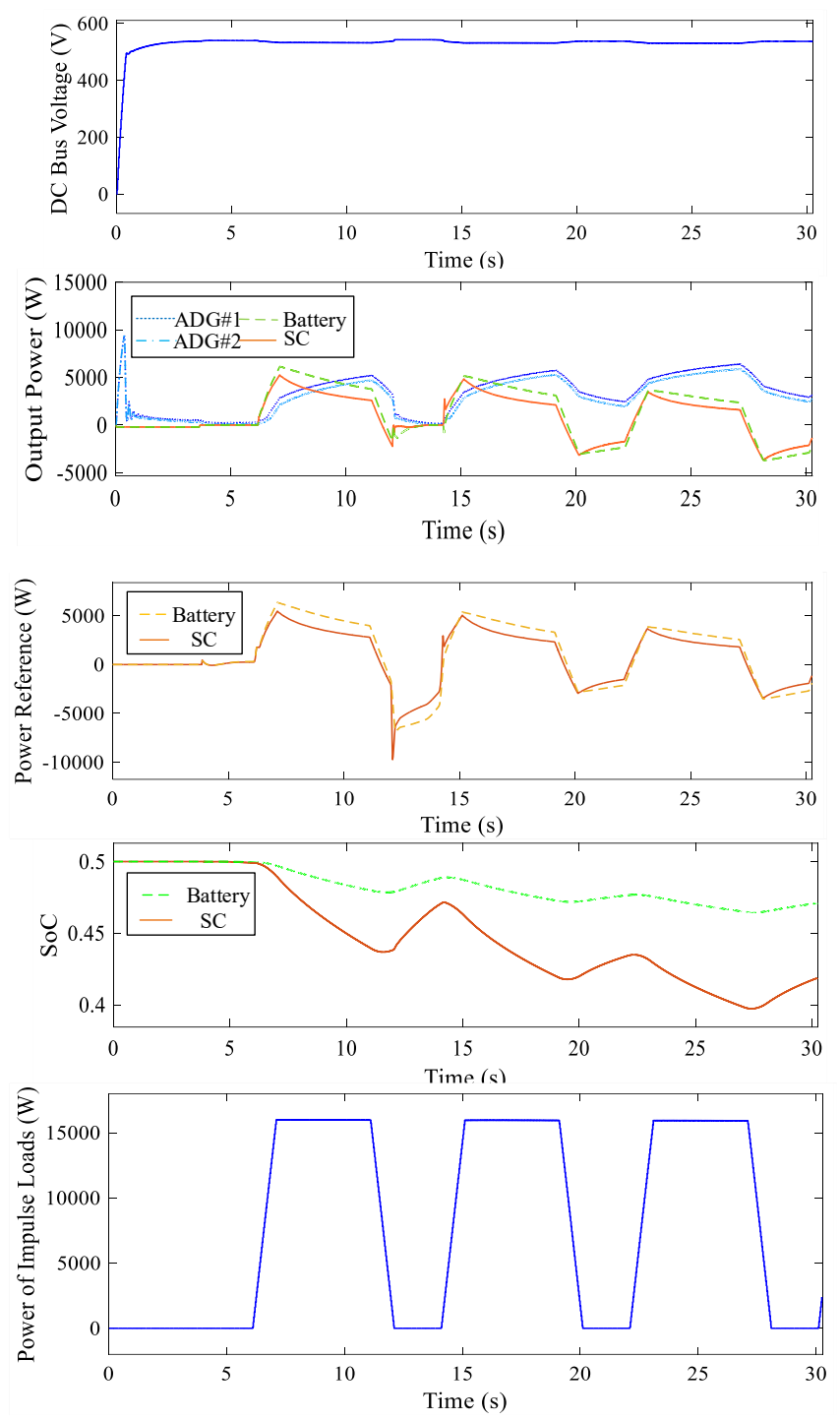

Fig. 8. Real-time simulation results of impulse loads

\section{CONCLUSION}

In this paper, an accurate power sharing of HESS based on quadratic programming algorithm in DC-SPS is presented; the main contributions can be summarized as follows.

1) Technical characteristics of different ESDs are considered in this paper, including rated capacity, ramp rate, efficiency, and real-time SoC. The power sharing between battery and SC through quadratic programming algorithm is presented as an example. By defining the cost function of energy storage, the algorithm can accurately quantify the responsibility of energy storage with different technical characteristics in voltage regulation control.

2) With the proposed method, the voltage drop of DC bus are compensated within allowable voltage range. Real-time simulation results show that the proposed method is effective and feasible.

\section{ACKNOWLEDGEMENTS}

This work is supported by the National Key R\&D Program of China (2017YFE0112400) and the European
Union's Horizon 2020 research and innovation programme under grant agreement No.734796.

\section{REFERENCES}

[1] Jun Hou, Jing Sun, and Heath F. Hofmann, "Mitigating power fluctuations in electric ship propulsion with hybrid energy storage system: Design and Analysis," IEEE Journal of Oceanic Engineering, vol. 43, no. 1, pp. 93-107, January 2018.

[2] Mohammed Masum Siraj Khan, Md Omar Faruque, and Alvi Newaz, "Fuzzy logic based energy storage management system for MVDC power system of all electric ship," IEEE Transactions on Energy Conversion, vol. 32, no. 2, pp. 798-809, June 2017.

[3] J. F. Hansen and F. Wendt, "History and state of the art in commercial electric ship propulsion, integrated power systems, and future trends," Proceedings of the IEEE, vol. 103, no. 12, pp. 2229-2242, December 2015.

[4] E. Skjong, R. V olden, E. Rodskar, M. Molinas, T. Johansen, and J. Cunningham, "Past, present and future challenges of the marine vessel's electrical power system," IEEE Transactions on Transportation Electrification, vol. 2, no. 4, pp. 522-537, December. 2016.

[5] Giorgio Sulligoi, Andrea Vicenzutti and Roberto Menis, "All-electric ship design: from electrical propulsion to integrated electrical and electronic power systems," IEEE Transactions on Transpoptation Electrification, vol. 2, no. 4, pp. 507-521, December 2016.

[6] Zheming Jin, Giorgio Sulligoi, Rob Cuzner, Lexuan Meng, Juan C. Vasquez, and Josep M. Guerrero, "Next-generation shipboard dc power system: introduction smart grid and dc microgrid technologies into maritime electrical netowrks," IEEE Electrification Magazine, vol. 4, no. 2, pp. 45-57, June 2016

[7] Zheming Jin, Lexuan Meng, Josep M. Guerrero and Renke Han, "Hierarchical control designfor a shipboard power system with dc distribution and energy storage aboard future more-electric ships," IEEE Transactions on Industrial Informatics, vol. 14, no. 2, pp. 703714 , February 2018.

[8] F. Jin, M. Wang, and C. Hu, "A fuzzy logic based power management strategy for hybrid energy storage system in hybrid electric vehicles considering battery degradation," 2016 IEEE Transportation Electrification Conference and Expo (ITEC), 2016, pp. 1-7.

[9] M. Michalczuk, B. Ufnalski, and L. Grzesiak, "Fuzzy logic control of a hybrid battery-ultracapacitor energy storage for an urban electric vehicle," 2013 8th International Conference and Exhibition on Ecological Vehicles and Renewable Energies, 2013, pp. 1-7.

[10] X. Lu, K. Sun, J. M. Guerrero, J. C. V asquez, and L. Huang, "Stateof-charge balance using adaptive droop control for distributed energy storagesystems in dc microgrid applications," IEEE Transactions on Industrial Electronics, vol. 61, no. 6, pp. 2804-2815, June 2014.

[11] X. Lu, K. Sun, J. M. Guerrero, J. C. V asquez, and L. Huang, "Doublequadrant state-of-charge-based droop control method for distributed energy storage systems in autonomous DC microgrids," IEEE Transactions on SmartGrid, vol. 6, no. 1, pp. 147-157, January 2015.

[12] V. Arcidiacono, A. Monti and G. Sulligoi, "Generation control system for improving design and stability of medium-voltage DC power system on ships," IET Electrical Systems in Transportation, vol. 6, no. 3. pp. 158-167, 2012.

[13] I. Lahbib, A. Lahyani, A. Sari and P. Venet, "Performance analysis of a lead-acid battery/supercapacitors hybrid and a battery stand-alone under pulsed loads," 2014 International Conference on Green Energy, 2014, pp. 273-278.

[14] Junyi Shen and Alireza Khaligh, “A supervisory energy management control strategy in a battery/ultracapacitor hybrid energy storage system," IEEE Transactions on Transportation Electrification, vol. 1, no. 3, pp. 223-231, October 2015.

[15] A. Solanki and A.Nasiri, "Energy storage size and fuel consumption reduction in a microgrid using virtual droop control framework," IEEE Energy Conversion Congress and Exposition, 2017, pp. 1-5.

[16] Olivier Mégel, Tao Liu, David J. Hill and Göran Andersson, "Distributed secondary frequency control algorithm considering storage efficiency," IEEE Transactions on Smart Grid, vol. 9, no. 6, pp. 6214-6228, November 2018. 